\title{
Residual Displacement Demand Evaluation from Spectral Displacement
}

\author{
Müberra ESER AYDEMİR ${ }^{1}$ \\ Cem AYDEMIR ${ }^{2}$
}

\begin{abstract}
In this study, residual displacement demands are investigated for SDOF systems with a period range of 0.1-3.0 s for near-field and far-field ground motions. The effects of stiffness degradation and post yield stiffness ratio in residual displacements are investigated. The modified-Clough model is used to represent structures that exhibit significant stiffness degradation when subjected to reverse cyclic loading. The elastoplastic model is used to represent non-degrading structures. For inelastic time history analyses, Newmark's step by step time integration method was adapted in an in-house computer program. Based on time history analyses, a new simple equation is proposed for residual displacement demand of a system as a function of structural period $(T)$, ductility $(\mu)$, strain hardening ratio $(\alpha)$ and spectral displacement $\left(\mathrm{S}_{\mathrm{d}}\right)$.
\end{abstract}

Keywords: Residual displacement, stiffness degradation, ductility demand, spectral displacement.

\section{INTRODUCTION}

Although it is preferable to design a structure that behaves elastically in the event of severe earthquake motions, current earthquake - resistant design provisions allow the nonlinear response of structures because of economic factors. Seismic design procedures aim at controlling earthquake damage to structural elements and many types of nonstructural elements by limiting lateral deformations on structures. Structural performance is usually estimated using peak deformation demands. However, the past earthquakes have shown that the excessive permanent lateral deformations at the end of the earthquake motion (i.e. residual displacement) of a system -in addition to peak demands- is one of the major parameters to determine whether the structural system can continue its function or the system should be strengthened/repaired or the system should be rebuilt. Besides, the necessity to

\footnotetext{
Note:

- This paper has been received on October 16, 2017 and accepted for publication by the Editorial Board on October 09, 2018.

- Discussions on this paper will be accepted by May 31, 2019.

- https://dx.doi.org/10.18400/tekderg.344597

1 İstanbul Aydın University, Dep. Of Civil Engineering, İstanbul, Turkey - muberraaydemir@aydin.edu.tr https://orcid.org/0000-0002-4609-4845

2 İstanbul Aydın University, Dep. Of Civil Engineering, İstanbul, Turkey - cemaydemir@aydin.edu.tr https://orcid.org/0000-0003-4531-5084
} 
consider the residual displacements and residual drifts in seismic performance assessment is addressed in Vision 2000 (1995) and FEMA356 (2000) guidelines. Therefore, it is important to estimate residual structural displacement demands for the evaluation and rehabilitation of structures.

Residual displacement ratios have been the topic of several investigations so far. The first well-known studies on residual displacement were conducted by Riddell and Newmark (1979a, b) pointing out that the magnitude of residual displacements is strongly affected by the unloading- reloading rules of the hysteresis model. Mahin and Bertero investigated the dispersion of the residual displacements of SDOF systems assuming a peak-ductility for each SDOF system (1981). MacRae and Kawashima (1997) worked on SDOF systems with ductility demands of 2, 4 and 6 for 11 ground motions. They concluded that post-yield stiffness has an important effect on the residual displacement levels. Similarly, to these previous studies, Pampanin et. al. (2002) worked on residual displacement ratios for equivalent SDOF systems for 20 earthquake motions and three different hysteretic models. They have concluded that without considering residual deformations, the performance of systems cannot be compared to other systems that sustain residual deformations. Ruiz Garcia and Miranda conducted the most extensive researches on residual displacement ratios for both SDOF and multistory structures (2005; 2006a, b; 2008). They proposed simplified expressions to estimate mean residual displacement ratios of existing structures and also, they reported that the amplitude and heightwise distribution of residual drift demands depend on the frame mechanism, structural overstrength and hysteretic behavior. Hatzigeorgiou et.al. (2011) and Christidis et.al. (2013) conducted parametric studies on SDOF systems to derive empirical equations for maximum displacement from residual displacements. More recently, Liossatou and Fardis (2014) investigated the effects of hysteresis rules representing the cyclic degradation of stiffness and strength and the energy dissipation of typical RC structures on residual displacement ratios whereas D'Ambrisi and Mezzi (2015) proposed a method to evaluate the residuals of the response parameters of a reinforced concrete plane frame. In a very recent study conducted by Ruiz Garcia and Guerrero (2017), a new functional form to estimate mean residual displacement ratios for soft soil sites is presented.

As all of these previous studies mainly focus on the normalized residual displacement ratios, the main difference lies in the definition of these ratios. For the case of residual displacements, several normalization alternatives have been proposed by various researchers. Mahin and Bertero (1981) and Farrow and Kurama (2003) used yield displacement to normalize residual displacement and they called this ratio as the residual displacement ductility. MacRae and Kawashima (1997) used maximum possible residual displacement demand for normalization. Pampanin et.al. (2002), Ruiz Garcia (2004), Ruiz Garcia \& Miranda (2005) and Borzi et.al. (2011) used the ratio of residual displacement to maximum inelastic displacement as the key parameter. Similarly, the ratio of residual displacement to elastic spectral displacement is used by Ruiz Garcia and Miranda (2005; 2006a, b; 2008); this ratio is called residual displacement ratio.

The objective of this study is to present the results of an investigation conducted to provide more information on the residual displacement for degrading and non-degrading structures when subjected to near-field and far-field earthquake ground motions. In particular, this study tried to: (1) investigate SDOF systems with a period range of 0.1-3.0 s and five levels of ductility $(\mu=2,3,4,5,6)$; (2) focus on elastoplastic and stiffness degrading structures with 
strain hardening ratios of $\alpha=-10 \%,-5 \%,-2 \%, 0,2 \%, 5 \%$ and $10 \%$; (3) use a set of nearfield and far-field ground motions and (4) propose a new equation for residual displacement demands of SDOF systems as a function of spectral displacement $(\mathrm{Sd})$, structural period $(\mathrm{T})$, ductility ratio $(\mu)$ and post yield stiffness ratio $(\alpha)$.

\section{ANALYSIS PROCEDURE}

\subsection{Hysteretic Behavior}

Numerous hysteretic models have been proposed to represent the cyclic behavior of reinforced concrete structures. One of the most common hysteretic models used for reinforced concrete structures is Modified-Clough model which is the improved form of the original model proposed by Clough and Johnston that includes the effect of stiffness degradation. This model is based on the Clough model, and several studies have concluded that the Modified-Clough model is more accurate and capable of reproducing the behavior of properly designed reinforced concrete structures (Miranda and Ruiz Garcia, 2002). The influence of stiffness degradation on the seismic demands of structures has been the topic of several studies (Clough and Johnston, 1966; Rahnama and Krawinkler, 1993; Gupta and Krawinkler, 1998; Gupta and Kunnath, 1998; Borzi et.al.,2011). In 2009, to enhance the understanding of degradation and dynamic instability by developing practical suggestions, where possible, to account for nonlinear degrading response in the context of current seismic analysis procedure FEMA P440A guideline was prepared (FEMA, 2009). Another research conducted by Ayoub and Chenouda (2009) has focused on the development of response spectra plots for inelastic degrading structural systems subjected to seismic excitations and conclusions regarding the behavior and collapse potential of different structural systems are drawn. Figure 1 shows the Elastoplastic (EP) and Modified-Clough (MC) hysteretic models.

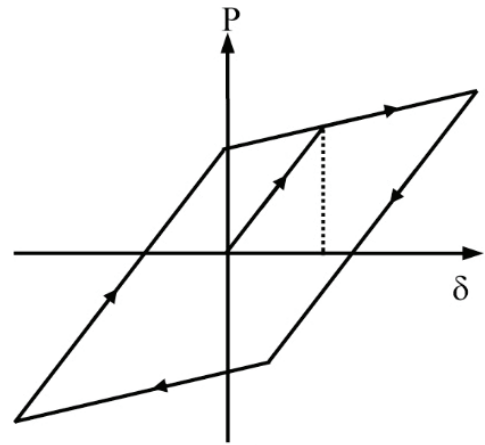

(a)

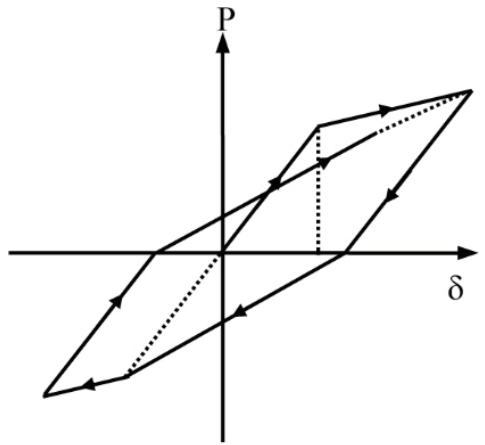

(b)

Fig. 1 - Load-deformation hysteretic models used in this study:

(a) Elastoplastic (EP); (b) Modified-Clough (MC)

The post yield stiffness ratio, $\alpha$ is the ratio of the post-yield stiffness of a SDOF system to its elastic stiffness. An $(\alpha)$ value larger than zero implies hardening behavior and smaller than zero implies softening behavior. P- $\delta$ effect caused by gravity loads acting on the deformed configuration of the structure will always lead to a decrease in stiffness and effective strength 
and an increase in lateral displacements. If the P-delta effect causes a negative post-yield stiffness in any story, it may affect significantly the interstory drift and may lead to incremental collapse if the structure has not sufficient strength. Therefore, if certain target ductility is required, more strength must be provided for the structural system. In the present study, post yield stiffness ratios of $\alpha=-10 \%,-5 \%,-2 \%, 0,2 \%, 5 \%$ and $10 \%$ are considered, respectively, to study the strain hardening / softening effect on residual displacements.

\subsection{Method of Analysis and Seismic Input}

The present study focuses on residual displacement demands of SDOF systems with Elastoplastic (non-degrading) (EP) and Modified-Clough (degrading) (MC) hysteretic behavior with linear hardening or softening. The dynamic equation of motion of an SDOF system is given by Eq. (1)

$$
m \ddot{u}+c \dot{u}+f_{s}(u)=-m \ddot{u}_{g}
$$

where $\mathrm{m}$ is the mass, $\mathrm{u}$ is the relative displacement, $\mathrm{c}$ is the viscous damping coefficient, $\int_{\mathrm{s}}(\mathrm{u})$ is the resisting force and $\ddot{u}_{\mathrm{g}}$ is the acceleration of ground motion. Newmark's step by step time integration method is adapted in an in-house computer program for inelastic time history analyses. Time history analyses were carried out with the time step selected as the minimum of followings; original earthquake ground motion time step, 1/25 of structural period and $0.01 \mathrm{~s}$.

Seismic excitation consists of real near-field and far-field earthquakes. A set of 70 near-field and 70 far-field acceleration time-histories are used in this study. The selection of near field and far field ground motions are based on the earthquakes given in ATC40 (1996) and ATC 63 (2007) documents. Details of selected ground motions are listed in Tables 1 and 2. Also, Figure 2 shows the magnitude- source distance- PGA relation for the far field and near field ground motions, respectively.
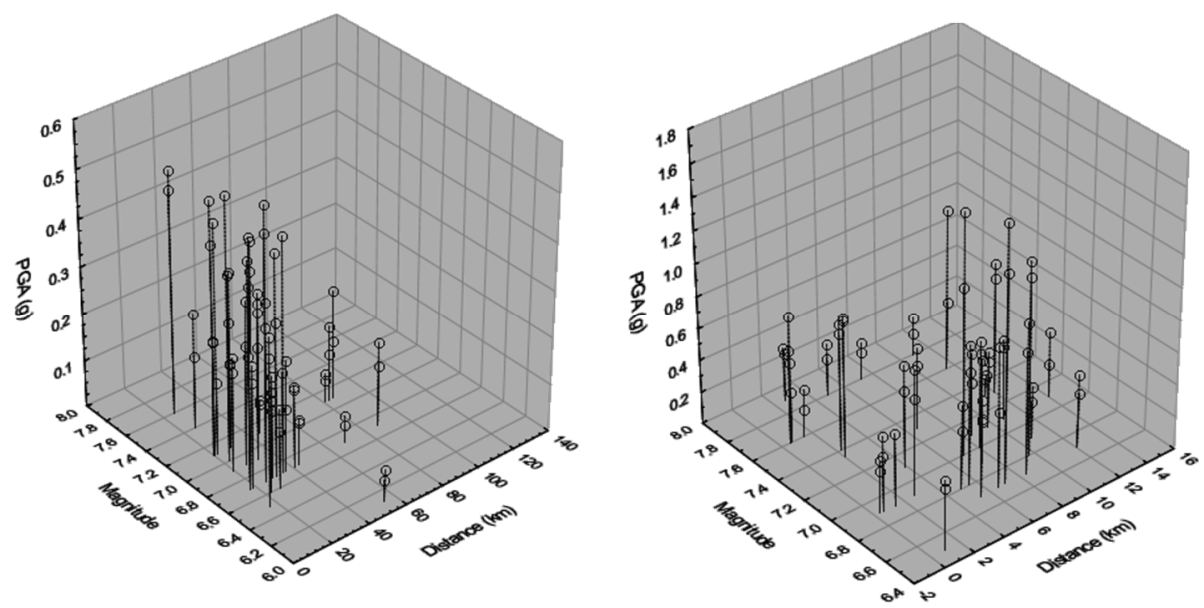

Fig. 2 - Magnitude- source distance-PGA relation for the used ground motions 
These accelerograms are downloaded from the strong motion database of the Pacific Earthquake Engineering Research (PEER) Center (Last access 2017). Near-field seismic ground motions are usually characterized by intense velocity and displacement pulses; besides, forward directivity and permanent translation are generally the two main causes for the velocity pulses observed in near-field regions. Thus, the near-fault ground motion data set is evaluated in detail to distinguish records that contain pulse-like signal effects. The nearfield ground motion set used for the presented study consists of 30 records with pulse signal and 40 records without pulse signal. The residual displacement demands are described separately for near-fault records that either do or do not contain pulse signals.

A total of 294000 analyses have been conducted for SDOF structures with period range of 0.1-3.0 s, five levels of ductility $(\mu=2,3,4,5,6), 140$ ground motions, seven strain hardening ratios $(\alpha=-10 \%,-5 \%,-2 \%, 0,2 \%, 5 \%, 10 \%)$ and two types of hysteretic behavior (EP and $\mathrm{MC})$.

\section{RESULTS AND DISCUSSION}

As mentioned before, for residual displacement demands, several normalization alternatives have been proposed by various researchers. For simplicity, it is generally appropriate to normalize the residual displacements $\left(\mathrm{D}_{\text {res }}\right)$ with respect to elastic spectral displacement $\left(\mathrm{S}_{\mathrm{d}}\right)$ of a SDOF system subjected to same acceleration time history which is called residual displacement ratio and is expressed as follows:

$$
D_{s}=\frac{D_{r e s}}{S_{d}}
$$

Thus, the results of conducted statistical study have been presented in the terms of residual displacement demands $\left(D_{\text {res }}\right)$ and residual displacement ratios $\left(D_{s}\right)$, respectively. The effects of analysis variables on these parameters are given below.

\subsection{Effect of Hysteretic Behavior}

\subsubsection{Effect of stiffness degradation}

In Figure 3, variations of mean residual displacement demands $\left(\mathrm{D}_{\text {res }}\right)$ against ductility are shown for elastoplastic and Modified Clough hysteretic models with strain hardening ratio of $0 \%$. The results are presented for far field ground motions set. It can be seen from the figure that; residual displacement demands of elastoplastic systems are almost always larger than degrading systems for all strain hardening ratios.

The variations of mean residual displacement ratios $\left(D_{s}\right)$ for Elastoplastic and Modified Clough hysteretic models for far field ground motion sets shown in Figure 4. It can be seen from the figures that mean residual displacement ratios are greater for elastoplastic systems than degrading systems for all strain hardening ratios. For all cases, it is observed that residual displacement ratios remain nearly constant for $\mathrm{T}>0.5 \mathrm{~s}$. For $\mathrm{T}<0.5 \mathrm{~s}$, there is tendency for residual displacement ratio to increase with the ductility demand. 


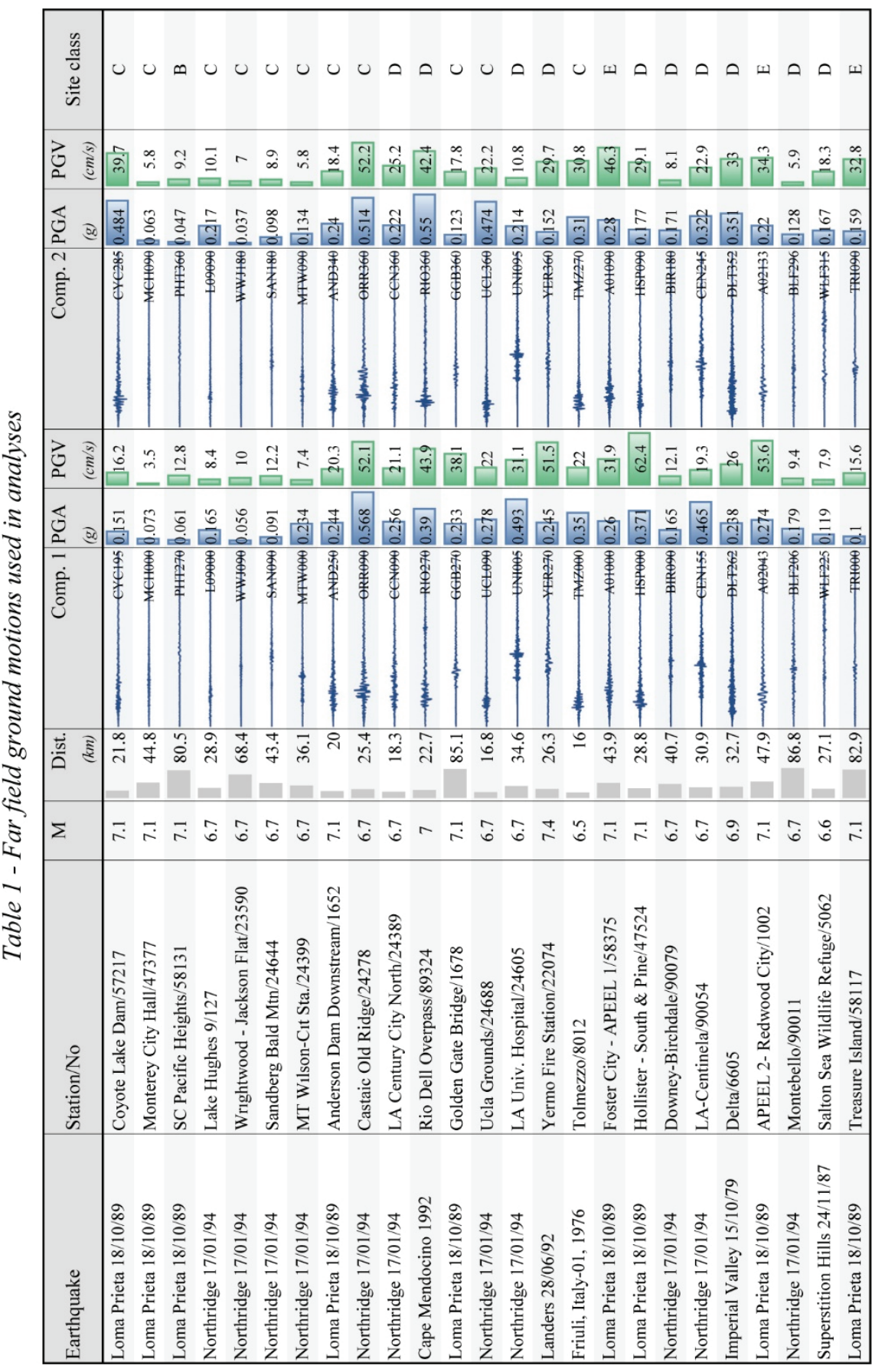



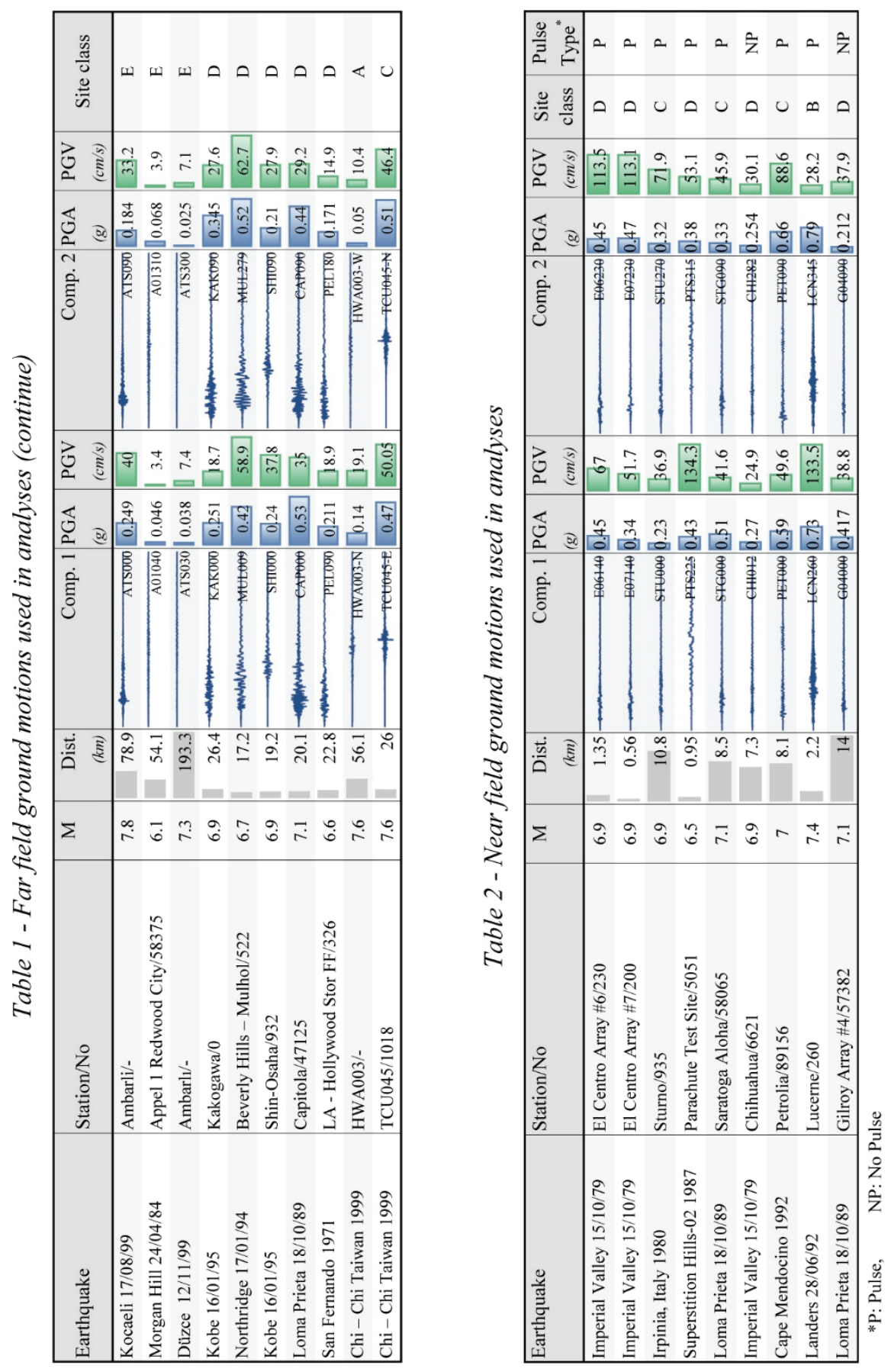


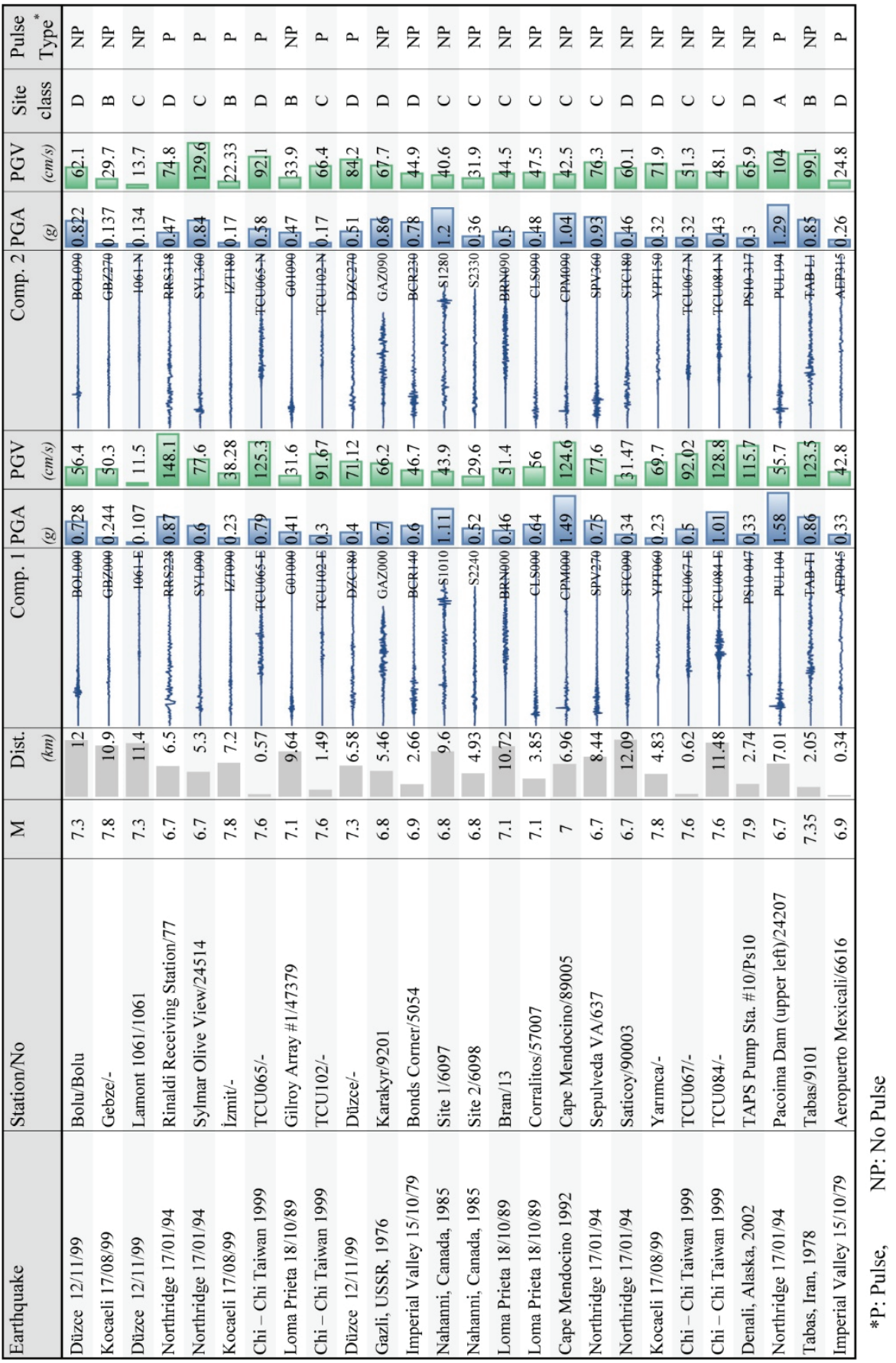




\subsubsection{Effect of post yield stiffness ratio}

In Figure 5, variations of mean residual displacement demands $\left(\mathrm{D}_{\text {res }}\right)$ against strain hardening ratio are shown for elastoplastic (left) and Modified Clough (right) hysteretic models. The results are presented for a system with ductility demand of 4.
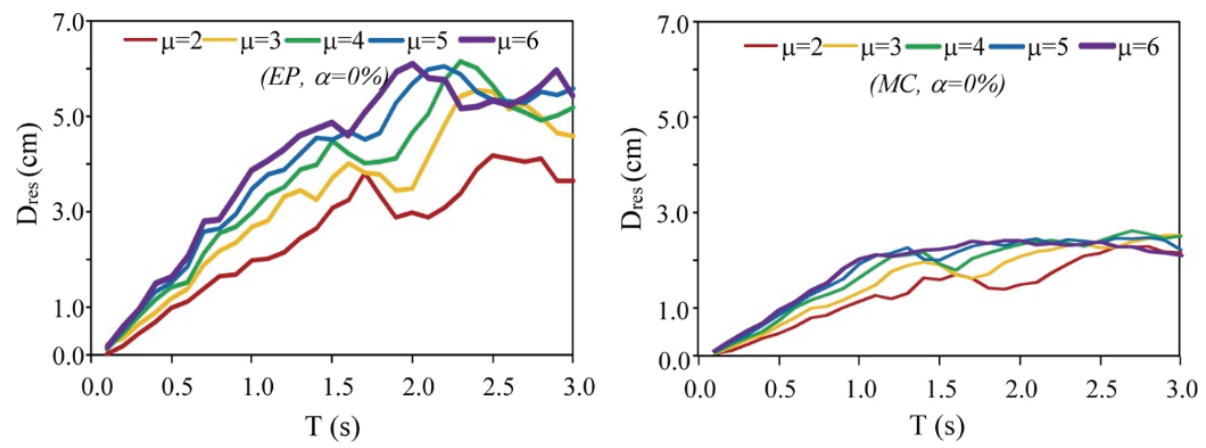

Fig. 3 - Variations of mean residual displacements against ductility for EP (left) and MC (right) behavior using far field ground motions for $0 \%$ hardening ratio
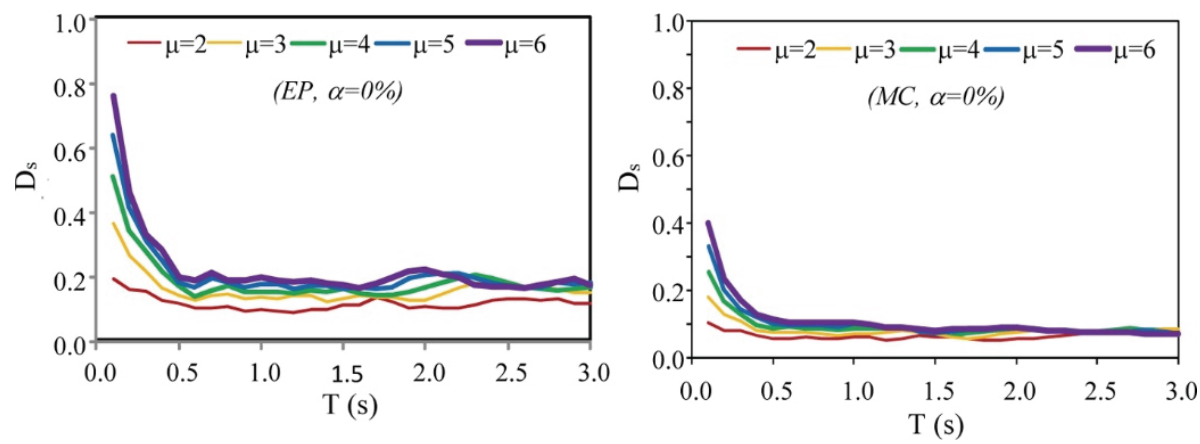

Fig. 4 - Variations of mean residual displacement ratio against ductility for EP (left) and $M C$ (right) behavior using far field ground motions for $0 \%$ hardening ratio

The top and bottom graphs in Figure 5 represent the results for far field ground motions and near field ground motions, respectively. It can be seen from the figure that, strain hardening / softening has a significant effect on seismic response and residual displacement demands. As the post yield stiffness ratio varies from positive to negative, residual displacement demands increase severely. The increase rate of residual displacement demand is 7-10 times for elastoplastic systems whereas the corresponding value is 3-4 times for degrading systems. 

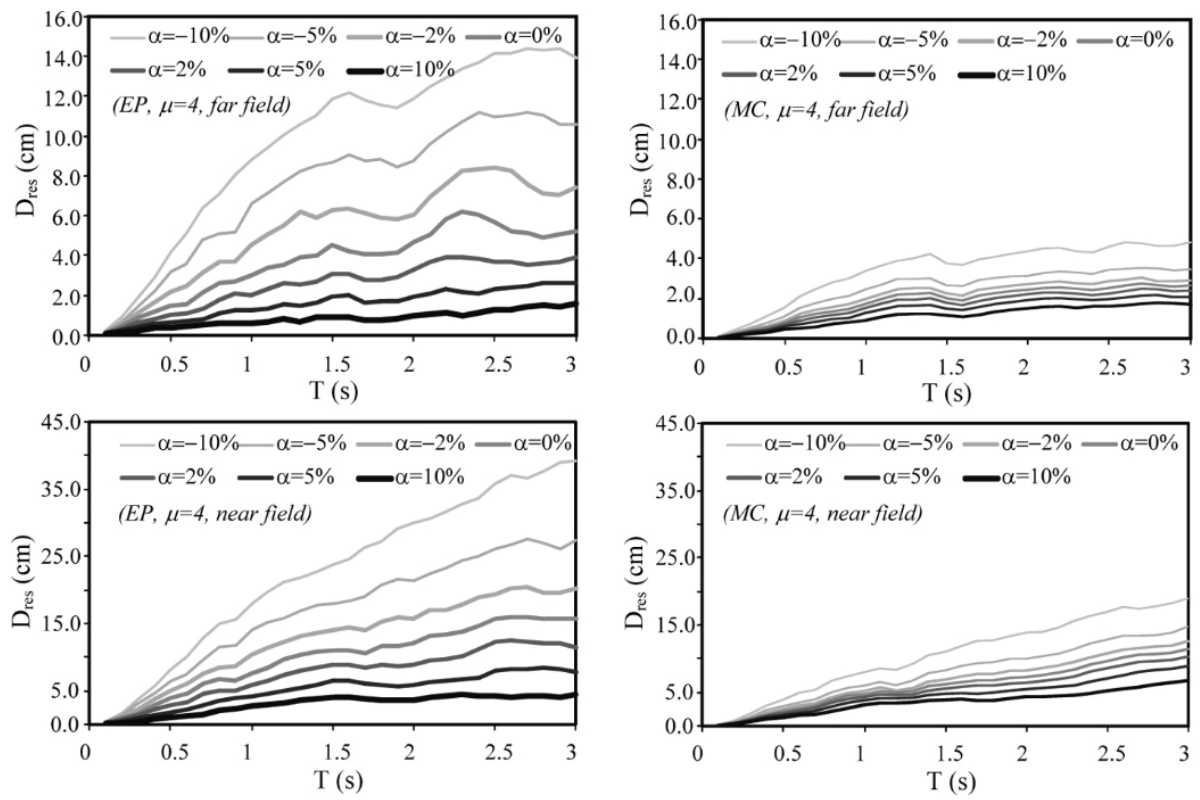

Fig. 5 - Variations of mean residual displacements against strain hardening ratio for EP (left) and MC (right) behavior using far field (upper) and near field ground motions (lower).
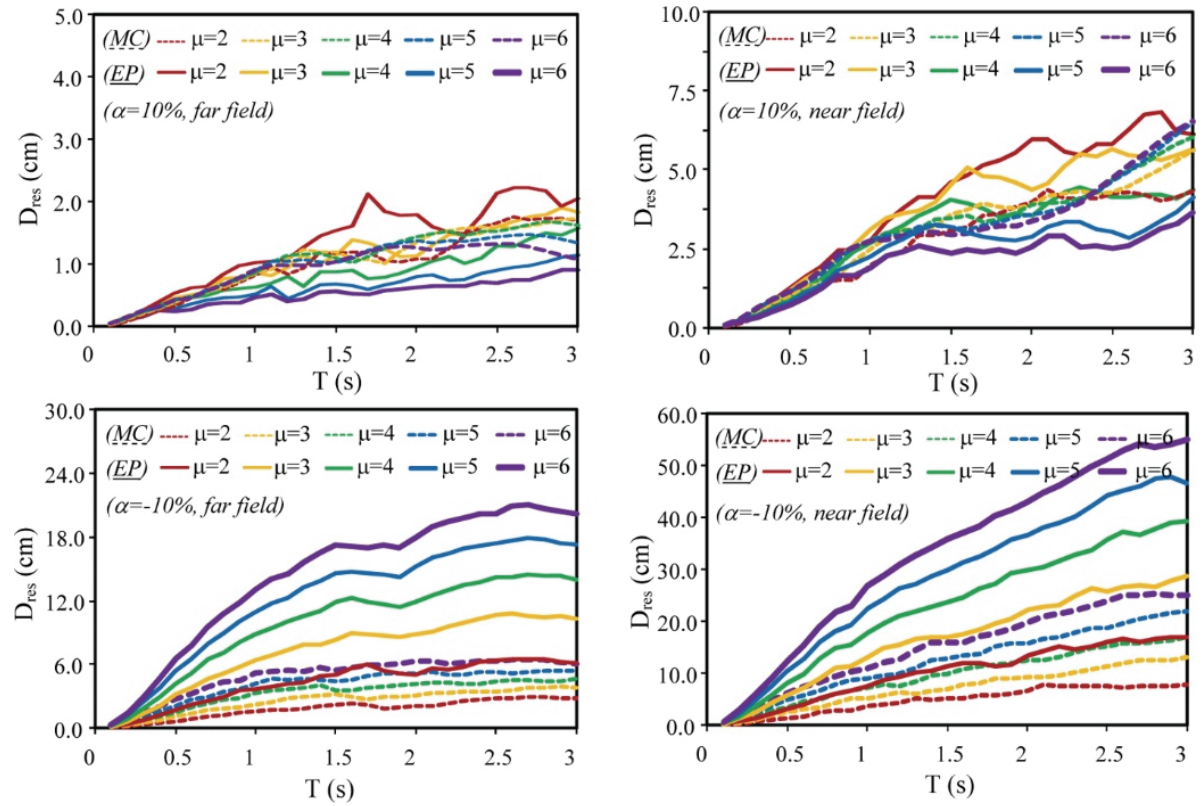

Fig. 6 - Variations of mean residual displacements for EP (solid line) and MC (dashed line) behavior using far field (left) and near field ground motions (right). 
In Figure 6, variations of mean residual displacement demands $\left(\mathrm{D}_{\text {res }}\right)$ with hysteretic model are shown together. The results are presented for two different strain hardening ratios. For negative post yield stiffness ratio, in other words strain softening case, residual displacement demands increase as the ductility demands increase. Besides, elastoplastic residual displacement demands are always greater than the corresponding ones of degrading model. But, as the post yield stiffness ratio is positive -strain hardening case- the relation between the residual displacement demand and ductility changes significantly. The minimum residual displacement demands occur when the ductility demand is the maximum for the positive post yield stiffness ratio as can be seen in top graphs in Figure 6.

In Figure 7, variations of mean residual displacement ratios $\left(D_{s}\right)$ against strain hardening ratio is shown for elastoplastic and degrading hysteretic models. The results are presented for a system with ductility demand of 4 . The top graphs represent the results of far field ground motion set whereas the bottom graphs correspond to the results of near field ground motion set. It can be seen from the figure that, as the post yield stiffness ratio varies from positive to negative, mean residual displacement ratios increase severely. Although the residual displacement ratio variation is very close to each other for stiffness degrading systems, there is an evident difference between the residual displacement ratios of elastoplastic systems.
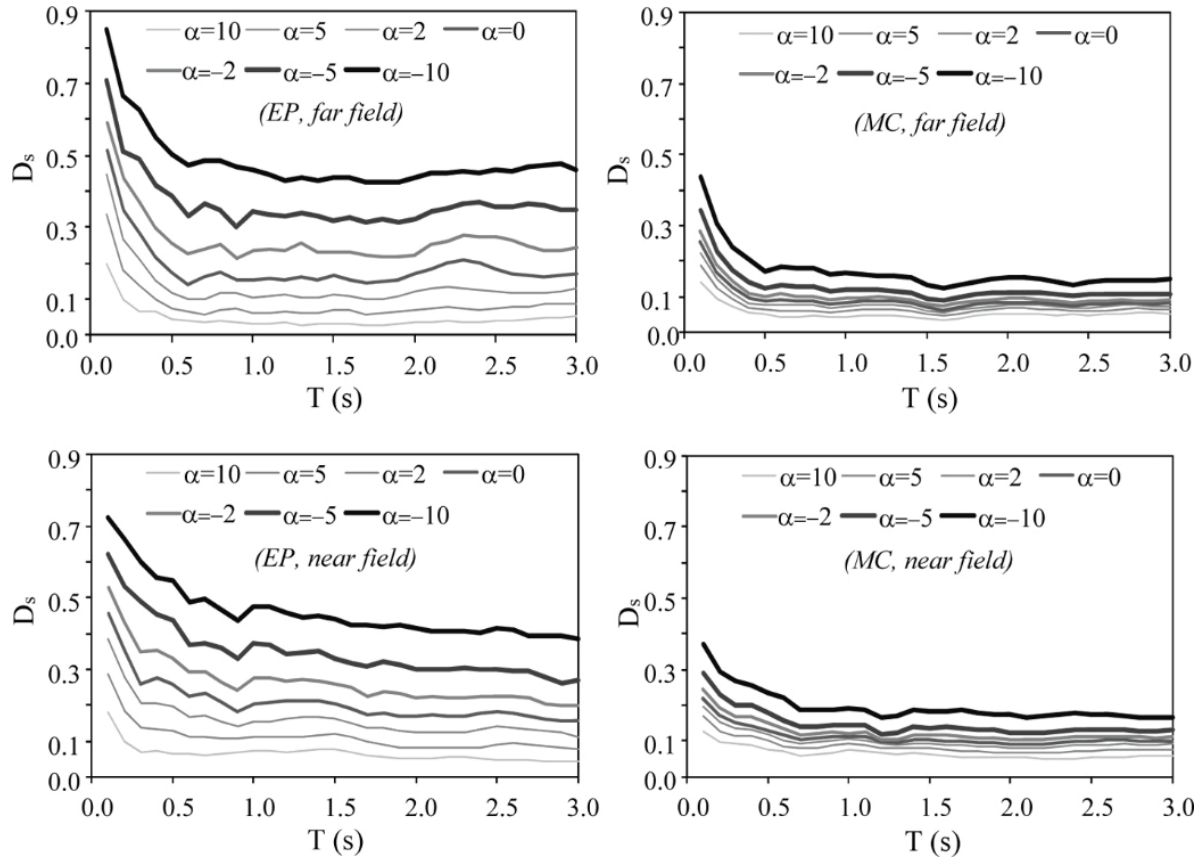

Fig. 7 - Variations of mean residual displacement ratio against strain hardening ratio for EP (left) and MC (right) behavior using far field (upper) and near field ground motions (lower). 


\subsection{Effect of Ground Motions}

\subsubsection{Effect of fault distance}

The effects of near and far field data on residual displacement demands $\left(D_{\text {res }}\right)$ are shown in Figure 8 for elastoplastic and Modified Clough hysteretic models for different values of post yield stiffness ratio. The solid lines represent the results for far field ground motions whereas the dashed lines show the results for near field ground motions. It can be seen from the figures that; residual displacement demands for near field ground motions are greater than the ones for far field ground motions. This condition is almost always valid for both hysteretic models and all post yield stiffness ratios.
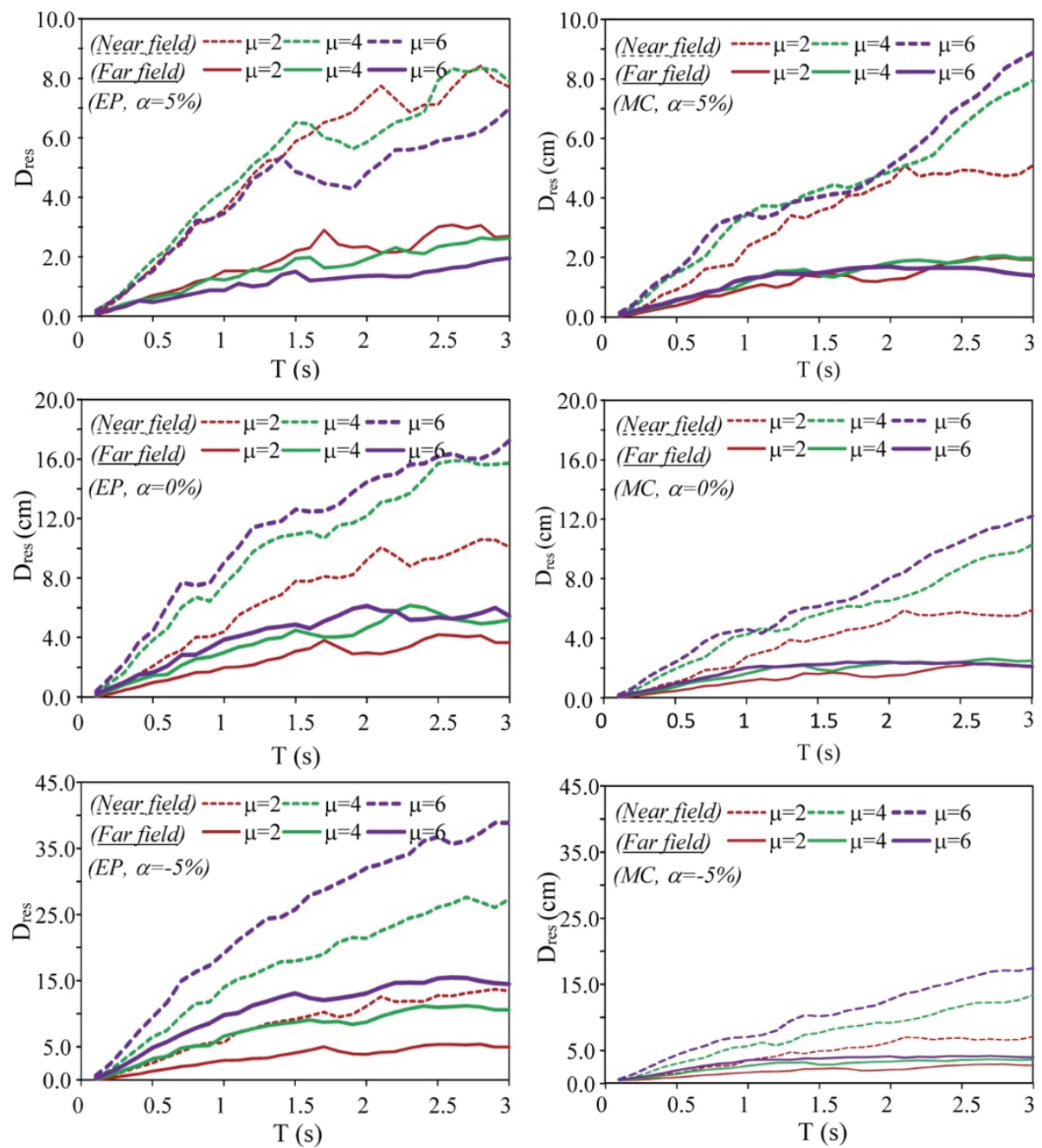

Fig. 8 - Variations of mean residual displacements for EP (left) and MC (right) behavior using far field (solid) and near field ground motions (dashed) 
Figure 9 shows the effects of near and far field data on residual displacement ratios $\left(D_{s}\right)$. Results are presented for elastoplastic and Modified Clough hysteretic models and different values of post yield stiffness ratio. The solid lines represent the results for far field ground motions whereas the dashed lines show the results for near field ground motions. It is seen from the figures that mean residual displacement ratios of near and far field ground motions are quite similar to each other within the period range covered and remain nearly constant especially for $\mathrm{T}>0.5 \mathrm{~s}$. This condition is almost always valid for both hysteretic models and all post yield stiffness ratios.
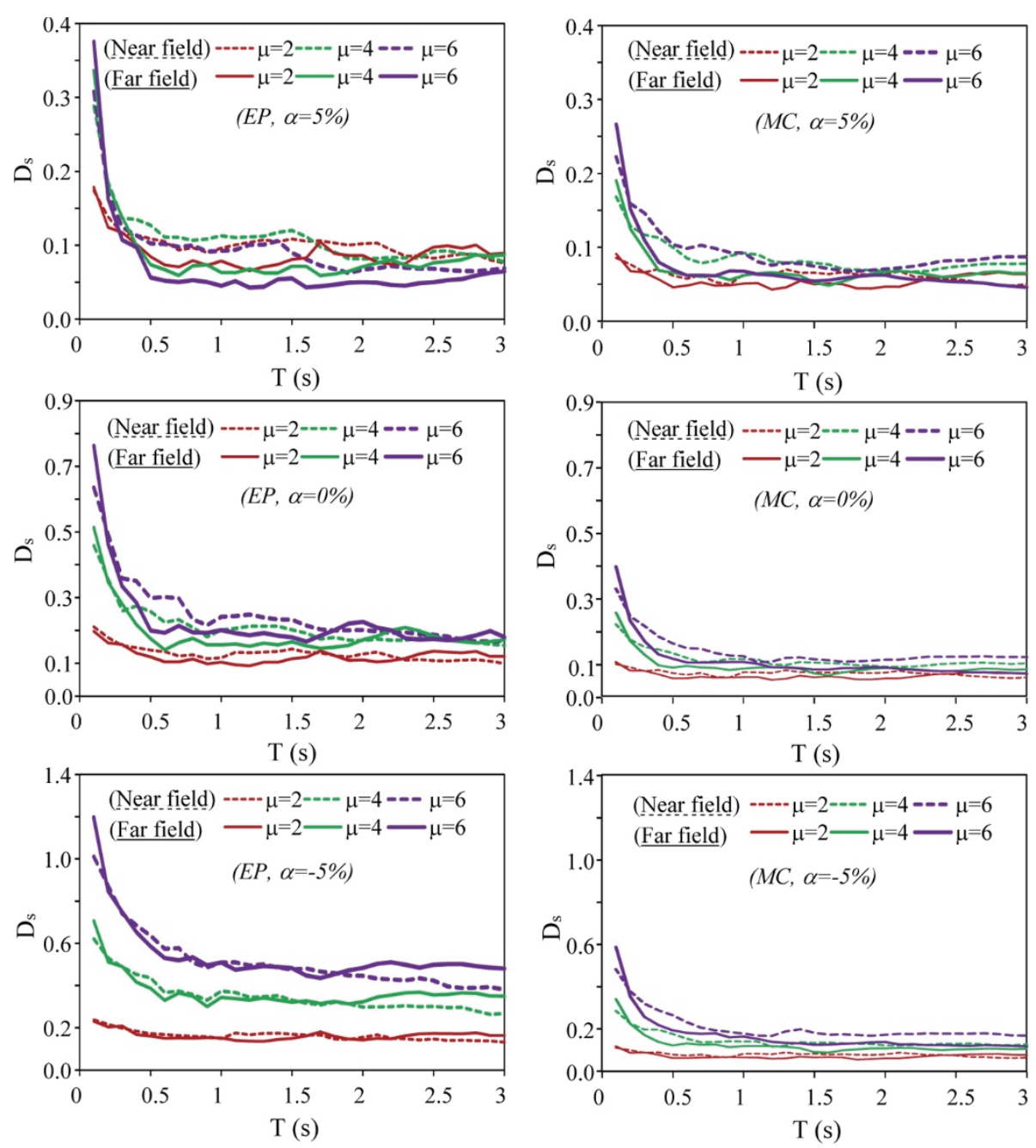

Fig. 9 - Variations of residual displacement ratios for EP (left) and MC (right) behavior using far field (solid) and near field ground motions (dashed) 


\subsubsection{Effect of pulse like features}

The effect of pulse like features for near field earthquakes on residual displacement demands is also investigated. In Figures 10 and 11, variations of mean residual displacement demands $\left(D_{\text {res }}\right)$ for pulse and no pulse type records are presented individually considering two hysteretic models and strain hardening ratios of $5 \%$ and $0 \%$. As it is seen from the figures, pulse like features have an obvious effect on residual displacement demands for both hysteretic models and strain hardening ratios. Although the same behavior is valid for other strain hardening ratios, they are not included in the figures for the sake of clarity.

The effect of pulse like features for near field earthquakes on mean residual displacement ratio is also investigated. In Figures 12 and 13, variations of mean residual displacement ratios $\left(D_{s}\right)$ for pulse and no pulse type records are presented.

It can be concluded from the figures that, the effects of pulse like features on mean residual displacement ratios are not as obvious as on residual displacement demands. This behavior is valid for other strain hardening ratios but they are not included in the figures for the sake of clarity.
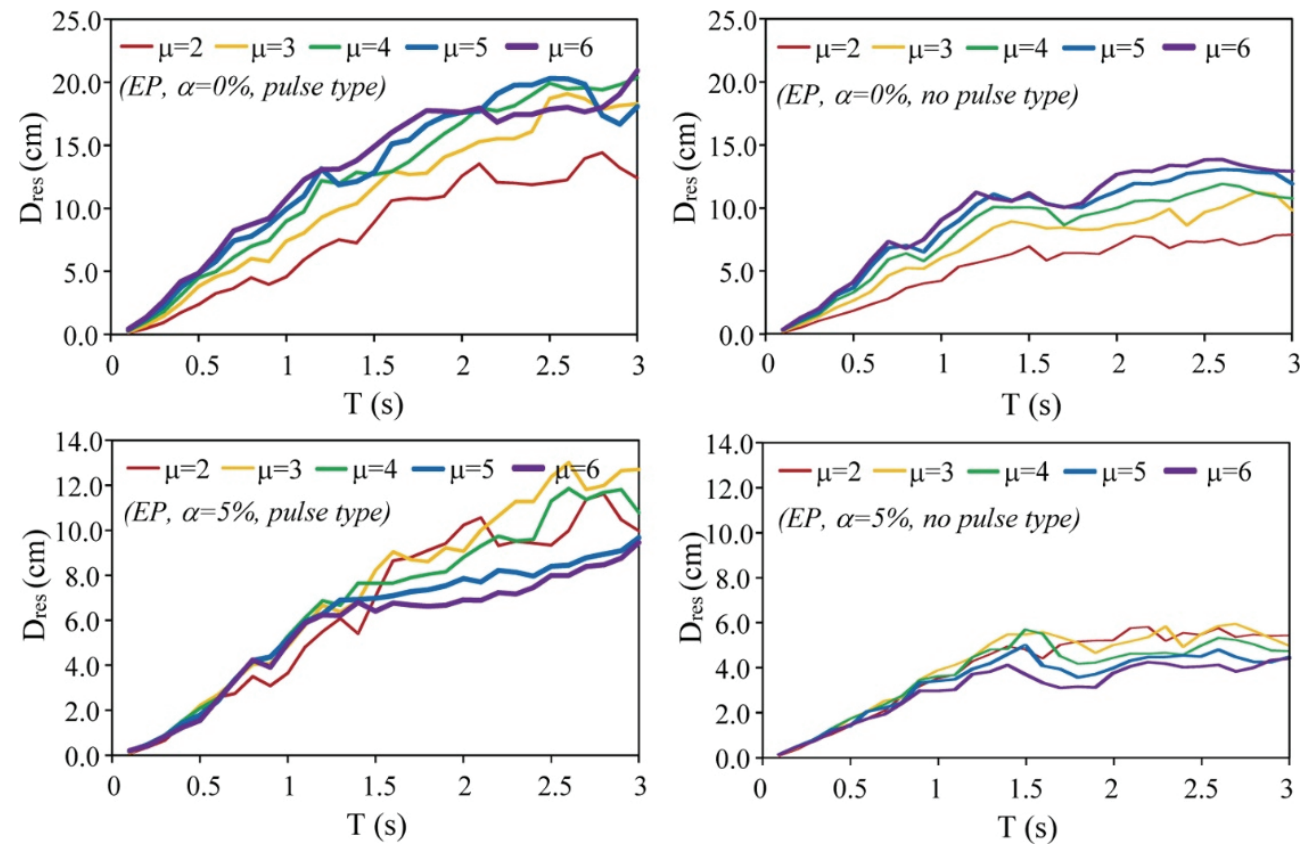

Fig. 10 - Variations of mean residual displacements for EP behavior using pulse type (left) and no pulse type ground motions (right). ( $\alpha=0 \%$ (upper), $\alpha=5 \%$ (lower)) 

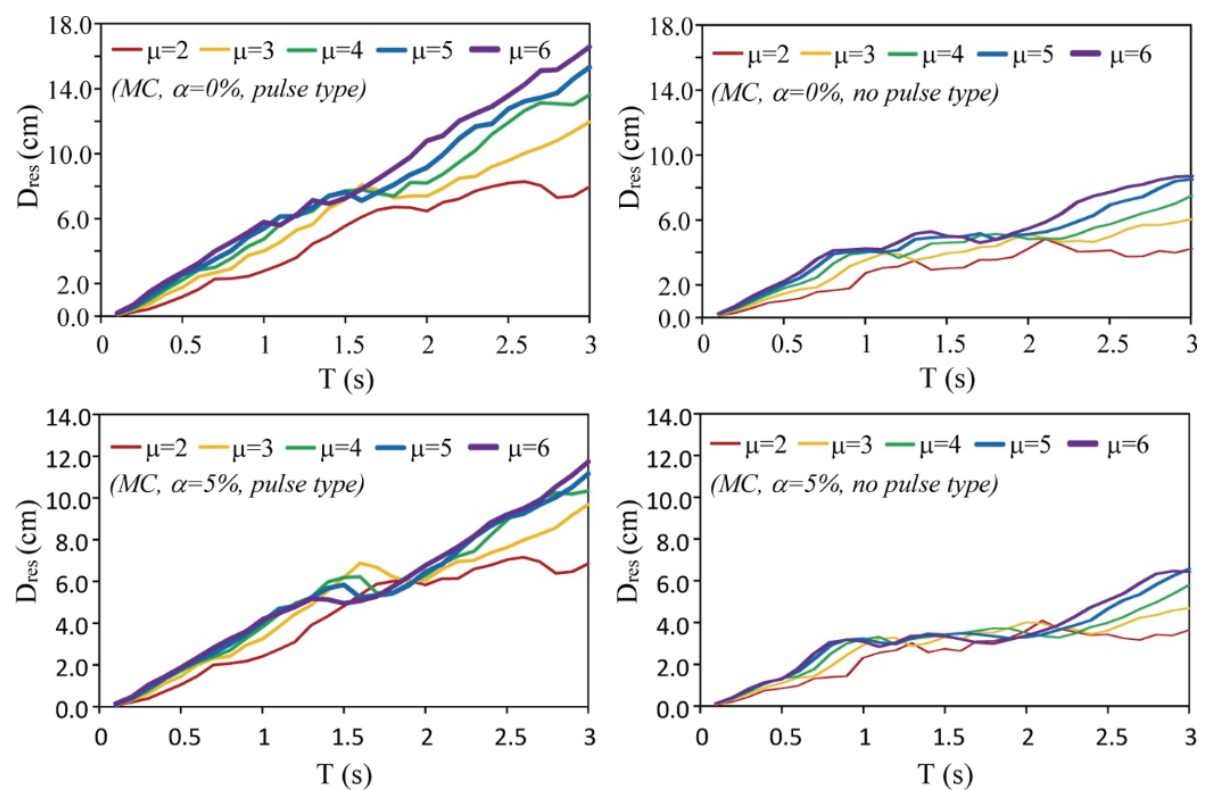

Fig. 11 - Variations of mean residual displacements for MC behavior using pulse type (left) and no pulse type ground motions (right). ( $\alpha=0 \%$ (upper), $\alpha=5 \%$ (lower))
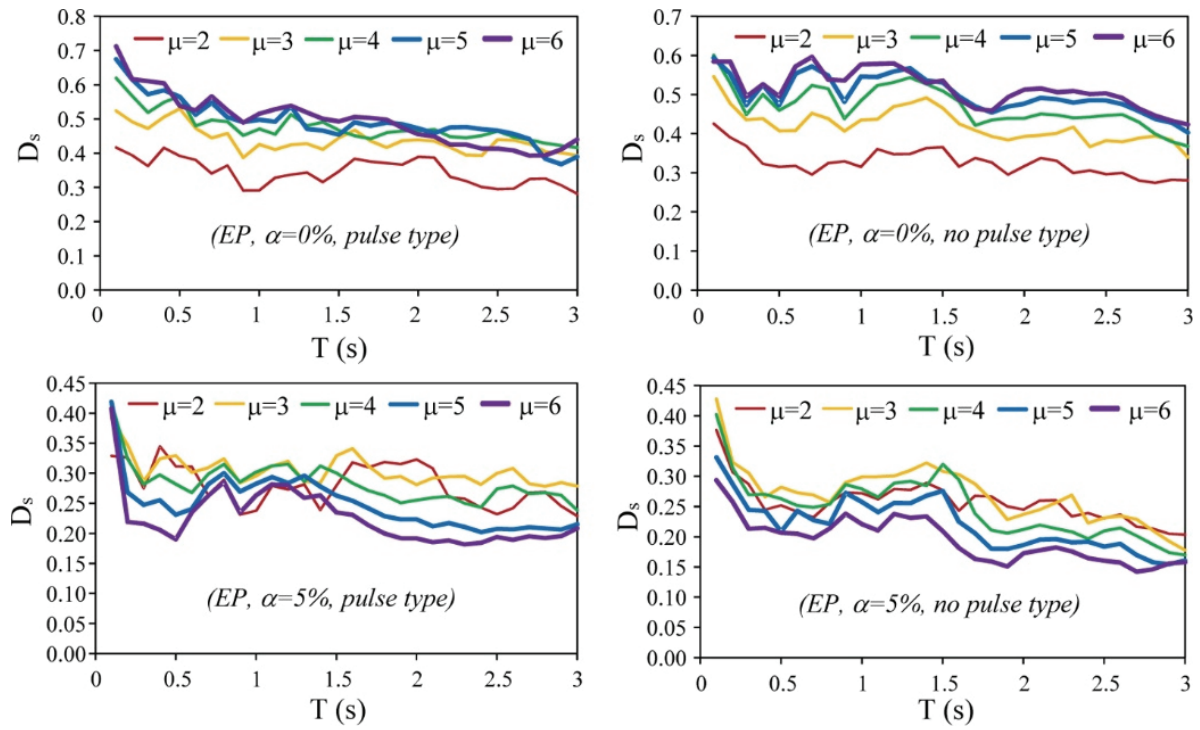

Fig. 12 - Variations of mean residual displacement ratios for EP behavior using pulse type (left) and no pulse type ground motions (right). ( $\alpha=0 \%$ (upper), $\alpha=5 \%$ (lower)) 

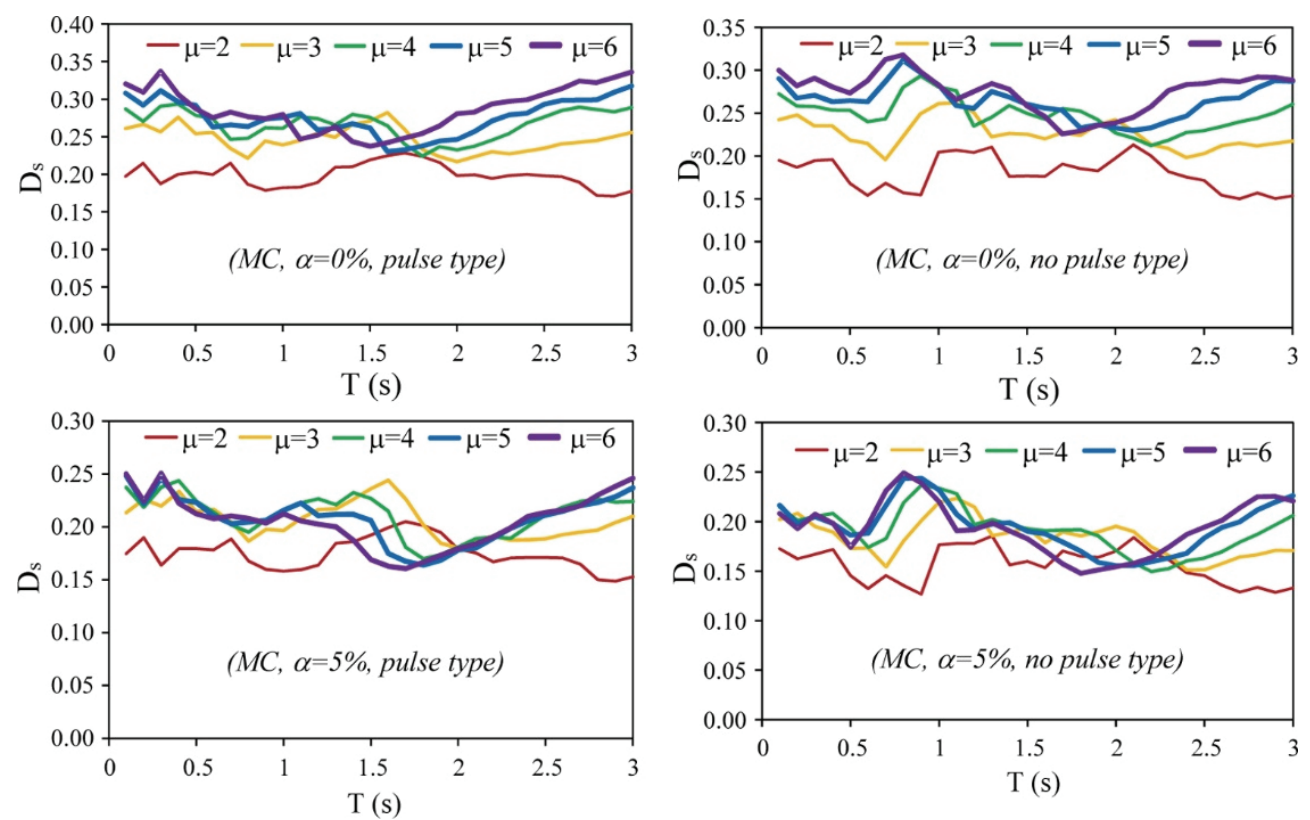

Fig. 13 - Variations of mean residual displacement ratios for MC behavior using pulse type (left) and no pulse type ground motions (right). ( $\alpha=0 \%$ (upper), $\alpha=5 \%$ (lower))

\section{SIMPLIFIED EQUATION TO ESTIMATE RESIDUAL DISPLACEMENTS}

A complete nonlinear regression analysis is carried out on the basis of the data obtained by the procedure described above. Correlations of structural variables on residual displacements are presented in Table 3. As it is seen from the matrix, the most effective parameters on residual displacement are spectral displacement and post yield stiffness ratio. Moreover, the correlation between spectral displacement and structural period is 0.7 , a relatively high value as expected. Thus, a simplified equation to predict residual displacement would include these parameters as variables.

Table 3 - Correlation matrix of structural variables on mean residual displacement values

\begin{tabular}{|cccccc|}
\hline & $\begin{array}{c}\text { Ductility ratio } \\
(\mu)\end{array}$ & $\begin{array}{c}\text { Period } \\
(\mathrm{T})\end{array}$ & $\begin{array}{c}\text { Post yield } \\
\text { stiffness ratio } \\
(\alpha)\end{array}$ & $\begin{array}{c}\text { Spectral } \\
\text { displacement } \\
\left(\mathrm{S}_{\mathrm{d}}\right)\end{array}$ & $\begin{array}{c}\text { Residual } \\
\text { displacement } \\
\left(\mathrm{D}_{\text {res }}\right)\end{array}$ \\
\cline { 2 - 6 }$\mu$ & 1.00 & & & & \\
$\mathrm{~T}$ & 0.00 & 1.00 & & & \\
$\alpha$ & 0.00 & 0.00 & 1.00 & 1.00 & \\
$\mathrm{~S}_{\mathrm{d}}$ & 0.00 & 0.70 & 0.00 & 0.61 & 1.00 \\
$\mathrm{D}_{\text {res }}$ & 0.22 & 0.42 & -0.55 & & \\
\hline
\end{tabular}


Using the Levenberg-Marquardt method (More, 1977) in the regression module of STATISTICA (1995), nonlinear regression analyses were conducted to derive simplified expressions for estimating mean residual displacements for elastoplastic and stiffness degrading models, respectively. The resulting regression formula is appropriately simplified and expressed as;

$$
D_{\text {res }}=\beta \cdot S_{d}
$$

where $\beta\left(=D_{\mathrm{s}}\right)$ is given by

$$
\beta=\left(a+b \mu+c \alpha+d \mu T+e \mu \alpha+f \mu \alpha^{2}\right)
$$

and $\mu$ is ductility, $\mathrm{T}$ is period and $\alpha$ is post yield stiffness ratio. Although the expression of $\beta$ coefficient is proposed to be a quadratic surface equation, as given in Equation 5, some terms which are considered to be insignificant are dropped. It is also worth noting that, since the effects of pulse like features on mean residual displacement ratios $\left(D_{s}\right)$ are not appreciable, the coefficient of the proposed equation for near field case is obtained for all near field record data. The coefficients " $\mathrm{a}-\mathrm{f}$ " are summarized in Table 4 for considered hysteretic models.

\begin{tabular}{|c|c|c|c|c|c|c|c|}
\hline \multirow{2}{*}{ Model/ Record Set } & \multicolumn{6}{|c|}{ Coefficients of quadratic surface } & \multirow{2}{*}{$\begin{array}{c}\text { Correlation } \\
\text { Coefficient, } \\
\text { R }\end{array}$} \\
\hline & $\mathrm{a}$ & $\mathrm{b}$ & $\mathrm{c}$ & d & $\mathrm{e}$ & $\mathrm{f}$ & \\
\hline EP / Far field & 0.158 & 0.062 & 0.0161 & 0.0036 & -0.0177 & 0.00048 & 0.99 \\
\hline MC / Far field & 0.123 & 0.022 & 0.0044 & -0.0024 & -0.0043 & 0.00015 & 0.98 \\
\hline EP / Near field & 0.169 & 0.104 & 0.016 & -0.0173 & -0.0156 & 0.00040 & 0.99 \\
\hline MC / Near field & 0.092 & 0.0417 & 0.0068 & -0.0021 & -0.0055 & 0.00015 & 0.99 \\
\hline EP / Far+Near field & 0.167 & 0.0978 & 0.016 & -0.0144 & -0.0159 & 0.00041 & 0.99 \\
\hline MC / Far+Near field & 0.096 & 0.0374 & 0.0065 & -0.0013 & -0.0054 & 0.00015 & 0.99 \\
\hline $\mathrm{EP}+\mathrm{MC} /$ Far field & 0.140 & 0.0422 & 0.0102 & 0.00056 & -0.0110 & 0.00032 & 0.80 \\
\hline $\mathrm{EP}+\mathrm{MC} /$ Near field & 0.130 & 0.07297 & 0.0114 & -0.0097 & -0.0106 & 0.00028 & 0.87 \\
\hline All data & 0.132 & 0.0676 & 0.0112 & -0.0078 & -0.0106 & 0.00028 & 0.88 \\
\hline
\end{tabular}

Table 4 - Parameter Summary for Eq. (4)

It should be remembered that the proposed equation is valid for inelastic structures (i.e. $\mu \geq$ 2) since there is no residual displacement for elastic structures.

Figure 14 shows the fitness of the regressed function of the mean residual displacements for elastoplastic and stiffness degrading models for both near field and far field records, all ductility values and strain hardening ratios. In Figure 14, Elastoplastic and Modified Clough hysteretic models are presented on the left and right, respectively. The vertical axis shows the calculated $D_{\text {res }}$ values whereas the horizontal axis shows the corresponding values obtained with proposed equation Eq. (4). 

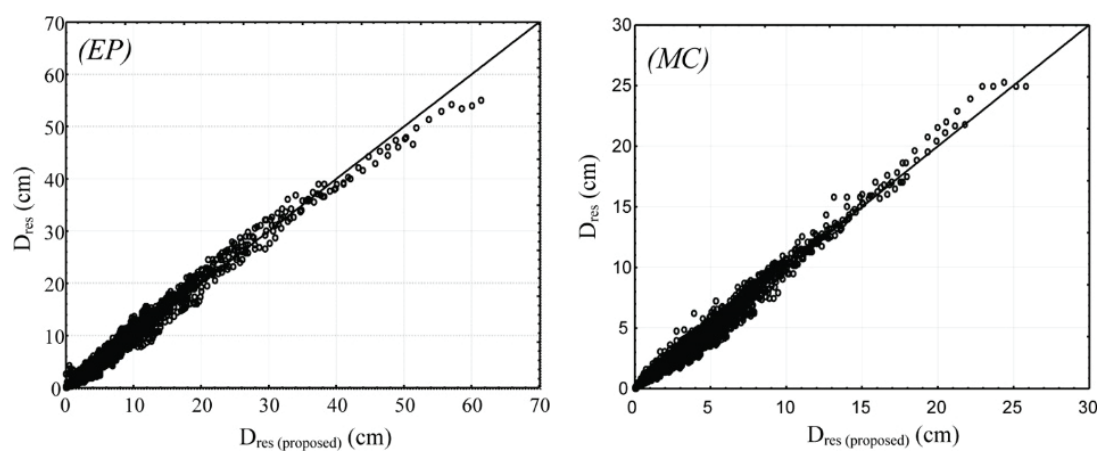

Fig. 14 - Comparison of calculated residual displacements with corresponding values obtained with proposed equation (Eq.4)
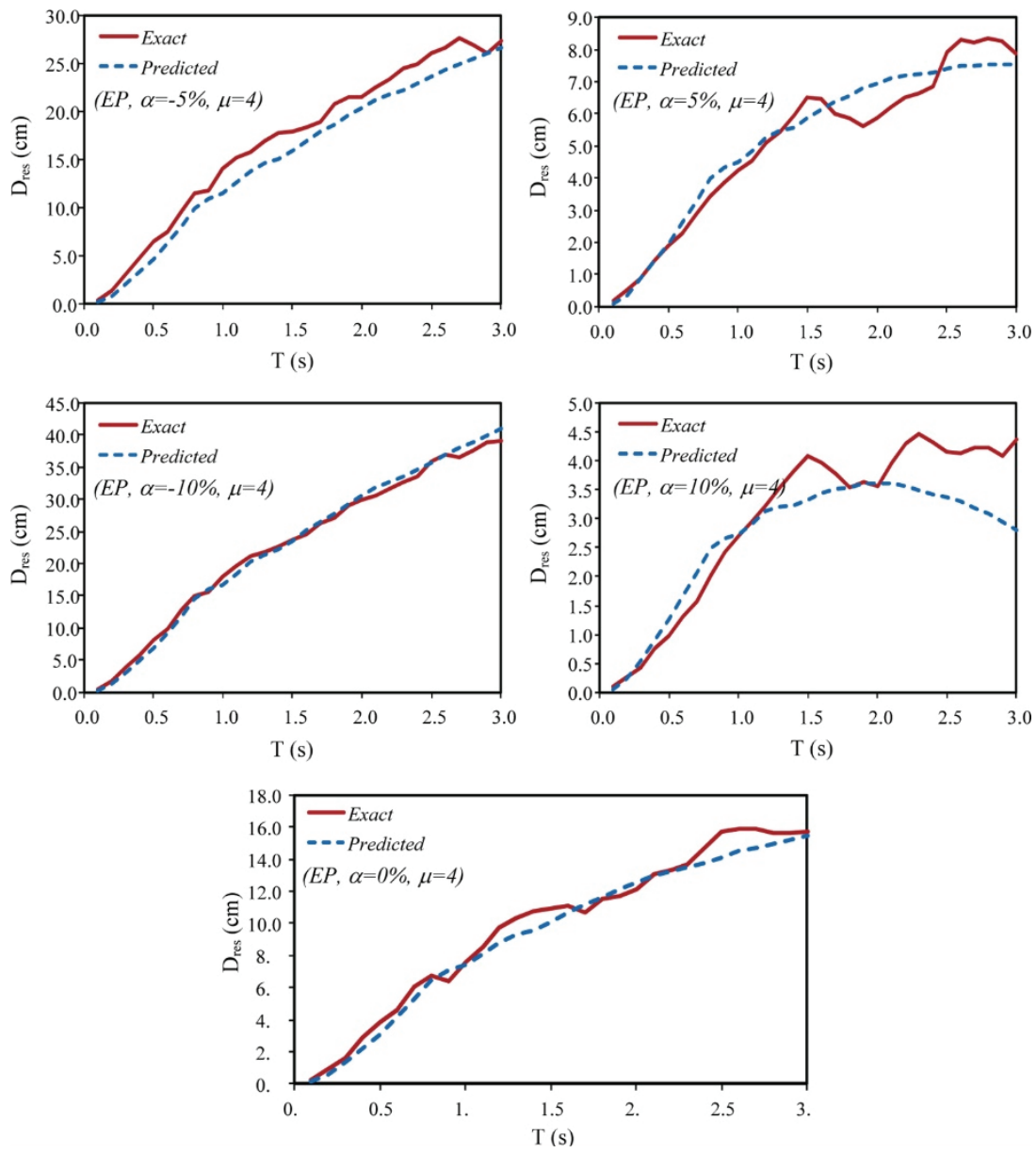

Fig. 15 - Comparison of exact (non-linear dynamic analysis) residual displacements (solid line) to those computed with Eq. (4) (dashed line). 

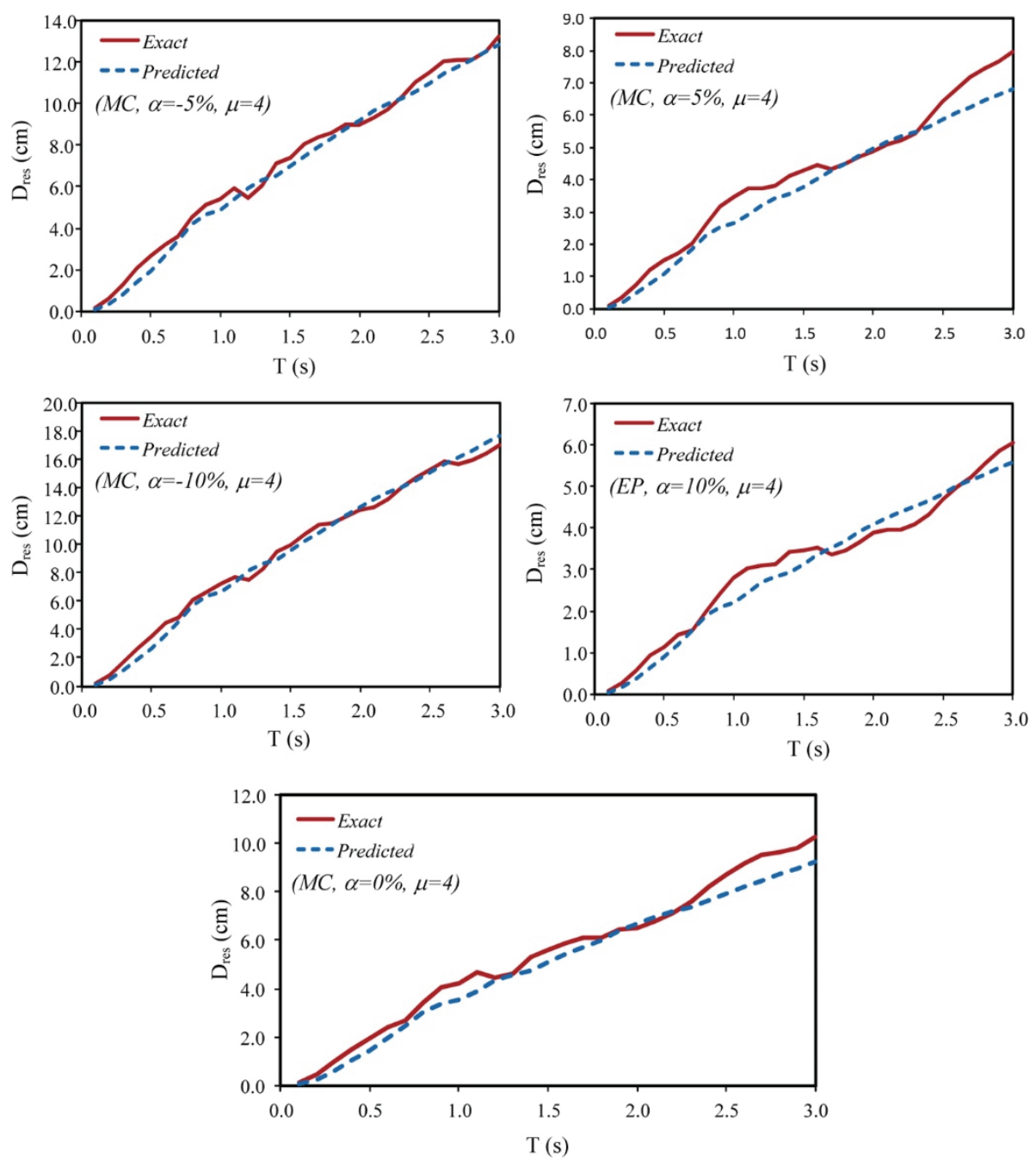

Fig. 16 - Comparison of exact (non-linear dynamic analysis) residual displacements (solid line) to those computed with Eq. (4) (dashed line).

Figures 15 and 16 demonstrate the fitness of the proposed function for the mean residual displacements for elastoplastic (EP) and Modified-Clough (MC) models, respectively. In these figures, the dashed line represents the values obtained from the proposed function (Eq.4) and the solid line represents the actual mean values of residual displacements obtained from non-linear dynamic analyses.

The comparison of proposed equation with existing residual displacement estimation equations is also completed. A very common measure of "goodness of fit" given by Eq. (6) is used for the comparison of proposed equation and the equation proposed by Ruiz Garcia 
and Miranda (2006c). The standard error values calculated for the cases considered are reported in Table 5. From these measures, it can be concluded that the proposed equation to estimate residual displacements provide good results.

$$
S E_{\text {of prediction }}=\sqrt{\left\{\frac{\sum\left(x_{\text {exact }}-x_{\text {predicted }}\right)^{2}}{n}\right\}}
$$

Table 2 - Computed Measures of "goodness of fit" for Eq. (4)

\begin{tabular}{|c|c|}
\hline Equation & $\begin{array}{c}\text { Standard } \\
\text { Error, SE }\end{array}$ \\
\hline Proposed eq. & 1.15 \\
Ruiz Garcia and Miranda (2006c) & 6.22 \\
\hline
\end{tabular}

\section{CONCLUSIONS}

In this study, residual displacement demands are investigated for SDOF systems with degrading and non-degrading behavior for a period range of 0.1-3.0 s considering far-field and near-field effects. For this purpose, the modified-Clough model is used to represent structures that exhibit significant stiffness degradation and the elastoplastic model is used to represent non-degrading structures. The effects of negative strain hardening on the displacement demand of structures are also investigated. A new equation is proposed for mean residual displacement demand of SDOF systems as a function of structural period (T), ductility ratio $(\mu)$, strain hardening ratio $(\alpha)$ and spectral displacement $\left(S_{d}\right)$. The following conclusions can be drawn from the results of this study.

- Residual displacement demands are larger for elastoplastic systems than degrading systems for all post yield stiffness ratios, under both far-field and near-field ground motion records. Besides, as the post yield stiffness ratio varies from positive to negative, the residual displacement variation presents a reverse behavior according to varying ductility demands. This is partially in agreement with earlier findings by other researchers such as Riddell and Newmark (1979a) and MacRae and Kawashima (1997).

- Residual displacement demands are found to be much greater for near field ground motion set rather than far field ground motions set. This statement is also in consistent with the results of study conducted by Farrow and Kurama (2003).

- Residual displacement ratios of near and far field ground motions are quite similar to each other for whole period range and remain nearly constant especially from the period point of $0.5 \mathrm{~s}$.

- Pulse like features of near field earthquakes have an obvious effect on residual displacement demands for both hysteretic models and strain hardening ratios. However, the effects of pulse like features on mean residual displacement ratios are not as obvious 
as on residual displacement demands because of the normalization using spectral displacement.

- As the post yield stiffness ratio varies from positive to negative, residual displacement demands increase drastically. The reason lies in the fact that, for systems with negative post-elastic stifnesses that the deformation is predominantly in one direction whereas for systems with positive post-elastic stifnesses the deformation is about the zero displacement position. The rate of increase is greater for elastoplastic systems than degrading systems.

- Similarly, to residual displacements, mean residual displacement ratios $\left(\mathrm{D}_{\mathrm{s}}\right)$ are greater for elastoplastic case rather than Modified Clough model for all strain hardening ratios and both ground motion sets. As the post yield stiffness ratio decreases, mean residual displacement ratios increase explicitly.

- A new equation (Eq. (4)) is proposed to represent the mean residual displacement demands for considered records, ductility values, strain hardening ratios and structural periods as a function of structural period $(\mathrm{T})$, ductility ratio $(\mu)$, strain hardening ratio $(\alpha)$ and spectral displacement $\left(\mathrm{S}_{\mathrm{d}}\right)$. The proposed simplified expression provide a good approximation of mean residual displacement ratios of SDOF systems having nondegrading or degrading behavior; with this simple equation, it is possible to obtain probable residual displacement demand of a system due to structural period, ductility and spectral displacement for any earthquake.

\section{References}

[1] Applied Technology Council (1996). ATC 40: The Seismic Evaluation and Retrofit of Concrete Buildings. 2 volumes. Redwood City, California.

[2] Applied Technology Council (2007). ATC 63: Recommended Methodology for Quantification of Building System Performance and Response Parameters - 75\% Interim Draft Report, Redwood City, California.

[3] Ayoub A, Chenouda M (2009). Response spectra of degrading structural systems. Engineering Structures, 31, 1393-1402.

[4] Borzi B, Calvi GM, Elnashai AS, Faccioli E, Bommer JJ (2011). Inelastic spectra for displacement-based seismic design. Soil Dynamics and Earthquake Engineering, 21(1), 47-61.

[5] Christidis AA, Dimitroudi EG, Hatzigeorgiou GD, Beskos DE (2013). Maximum seismic displacements evaluation of steel frames from their post-earthquake residual deformation. Bulletin of Earthquake Engineering, 11(6) : 2233-2248.

[6] Clough RW, Johnston SB (1966). Effect of stiffness degradation on earthquake ductility requirements. In: Proc of the Japan Earthquake Engineering Symposium, Tokyo, Japan, $227-232$. 
[7] D'Ambrisi A, Mezzi M (2015). Design value estimate of the residuals of the seismic response parameters of RC frames. Bulletin of Earthquake Engineering, 13(5), 14911511.

[8] Farrow KT, Kurama YT (2003). SDOF demand index relationships for performancebased design. Earthquake Spectra, 19(4):799-838.

[9] Federal Emergency Management Agency (2000). NEHRP guidelines for the seismic rehabilitation of buildings. ReportFEMA356:, Washington, DC.

[10] Federal Emergency Management Agency (2009), Effects of Strength and Stiffness Degradation on Seismic Response FEMA P440A, Washington, DC.

[11] Gupta A, Krawinkler H (1998). Effect of stiffness degradation on deformation demands for SDOF and MDOF structures. Proc., 6th Natl. Conf. on Earthquake Engineering, Earthquake Engineering Research Institute, Oakland, California.

[12] Gupta B, Kunnath SK (1998). Effect of hysteretic model parameters on inelastic seismic demands. Proc., 6th Natl. Conf. on Earthquake Engineering, Earthquake Engineering Research Institute, Oakland, California.

[13] Hatzigeorgiou GD, Papagiannopoulos GA, Beskos DE (2011). Evaluation of maximum seismic displacements of SDOF systems from their residual deformation. Engineering Structures, $33: 3422-3431$.

[14] Liossatou E, Fardis MN (2014). Residual displacements of RC structures as SDOF systems. Earthquake Engineering \& Structural Dynamics, doi: 10.1002/eqe.2483.

[15] MacRae GA, Kawashima K (1997). Post-earthquake residual displacements of bilinear oscillators. Earthquake Engineering \& Structural Dynamics, 26(7):701-716.

[16] Mahin SA, Bertero VV (1981). An evaluation of inelastic seismic design spectra. Journal of The Structural Division, ASCE, 107(9):1777-1795.

[17] Miranda E, Ruiz-Garcia J (2002). Influence of stiffness degradation on strength demands of structures built on soft soil sites, Engineering Structures, 24:(10), 1271-1281.

[18] More JJ (1977). Levenberg - Marquardt algorithm: implementation and theory. Conference on numerical analysis, Dundee, UK.

[19] Pacific Earthquake Engineering Research Center. PEER Strong motion database. http://peer.berkeley.edu/smcat. Last access: 2017

[20] Pampanin S, Christopoulos C, Priestley MJN (2002). Residual deformations in the performance-based seismic assessment of frame structures, No. ROSE-2002/02. Technical report, European School for Advanced Studies in Reduction of Seismic Risk, University of Pavia, Italy.

[21] Rahnama M, Krawinkler H (1993). Effects of soft soil and hysteresis model on seismic demands. Rep. No. 108, John A. Blume Earthquake Engineering Center, Stanford Univ., Stanford, California. 
[22] Riddell R, Newmark NM (1979a). Statistical analysis of the response of nonlinear systems subjected to earthquakes. Research Report 468. Un. of Illinois at UrbanaChampaign, Urbana, ILL, 291pp.

[23] Riddell R, Newmark NM (1979b). Force-deformation models for nonlinear analysis. Journal of Structural Division, ASCE, 105(12):2773-2778.

[24] Ruiz-Garcia J (2004). Performance-based assessment of existing structures accounting for residual displacements. Dissertation, Stanford University, California.

[25] Ruiz-Garcia J, Miranda E (2005). Performance-based assessment of existing structures accounting for residual displacements, No. 153. Technical report, The John A. Blume Earthquake Engineering Center, Stanford University, California.

[26] Ruiz-Garcia J, Miranda E (2006a). Evaluation of residual drift demands in regular multistorey frames for performance-based seismic assessment. Earthquake Engineering \& Structural Dynamics, 35(13):679-694.

[27] Ruiz-Garcia J, Miranda E (2006b). Residual displacement ratios of SDOF systems subjected to near-fault ground motions. Proceedings of the 8th. US National Conference on Earthquake Engineering, EERI, Paper No. 380, San Francisco, California.

[28] Ruiz-Garcia J, Miranda E (2006c). Residual displacement ratios for assessment of existing structures. Earthquake Engineering \& Structural Dynamics, 35:315-336.

[29] Ruiz-Garcia J, Miranda E (2008). Probabilistic seismic assessment of residual drift demands in existing buildings. In The 14th World Conference on Earthquake Engineering, Beijing, China.

[30] Ruiz-Garcia J, Guerrero H (2017). Estimation of residual displacement ratios for simple structures built on soft soil sites. Soil Dynamics \& Earthquake Engineering, 100: 555558.

[31] SEAOC (1995). Vision 2000: Performance based seismic engineering of buildings, Volume I. Technical report, Structural Engineers Association of California, Sacramento, California.

[32] StatSoft Inc (1995). STATISTICA V.12.0 for Windows. Tulsa, OK, USA. 
